\title{
Sudden in-hospital death after acute myocardial infarction in Cuba in the past 3 years: Analysis of institutional records
}

\section{Muerte súbita intrahospitalaria luego de infarto agudo de miocardio en Cuba en los últimos tres años. Análisis de registros institucionales}

\section{Miguel A. Rodríguez-Ramos ${ }^{1}$ and Maikel Santos-Medina ${ }^{2}$}

${ }^{1}$ Coronary Intensive Care Unit, Hospital General Docente Camilo Cienfuegos, Universidad de Ciencias Médicas Faustino Pérez Hernández, SanctiSpiritus; ${ }^{2}$ Coronary Intensive Care Unit, Hospital General Docente Ernesto Guevara, Universidad de Ciencias Médicas Zoilo Marinello Vidaurreta, Las Tunas, Cuba

\begin{abstract}
Objective: The objective of the study was to analyze possible predisposing causes of in-hospital sudden cardiac death (SCD) after an acute myocardial infarction (AMI) in Cuban registries. Materials and methods: $A$ search of clinical records of patients with AMI in Cuba was performed in the databases of national journals, Scientific Library On-line and Medline. Those articles published since 2016 were prioritized for inclusion. Sudden death (SD) is defined as that secondary to malignant ventricular arrhythmias (ventricular tachycardia and ventricular fibrillation) as well as patients with cardiac rupture with pulseless electrical activity or asystole as a form of presentation. Subsequently, the relationship of this parameter with the occurrence of $S D$ was evaluated in 710 patients from the Registry of Acute Coronary Syndromes. Results: In the out-of-hospital setting, more than half of SCD are secondary to an AMI. Once in the hospital, mortality in Cuba from AMI is homogeneous. Only centers with coronary interventionism escape this phenomenon. Although not totally lethal, the presence of malignant ventricular arrhythmias is associated with a worse prognosis and its prevalence is not homogeneous in the reviewed records. Conclusions: SD after AMI will continue to be one of the main causes of death of patients in the acute phase in Cuba.
\end{abstract}

Key words: Sudden cardiac death. Hospital mortality. Myocardial infarction. ST segment elevation acute myocardial infarction.

\section{Resumen}

Objetivo: Analizar el comportamiento de posibles causas predisponentes de muerte súbita (MS) intrahospitalaria luego de un infarto agudo de miocardio (IMA) en registros cubanos. Material y método: Se realizó una búsqueda de registros clínicos de pacientes con IMA en Cuba en las bases de datos de revistas nacionales, Scientific Library On-line (ScieLO) y Medline. Se priorizaron los artículos publicados desde 2016 para ser incluidos. Se definió como muerte súbita aquélla secundaria a arritmias ventriculares malignas (TV y FV), así como los pacientes con rotura cardíaca y actividad eléctrica sin pulso o asis-tolia como forma de presentación. Con posterioridad se evaluó la relación de este parámetro con la aparición de muerte súbita en 710 pacientes del Registro de Síndromes Coronarios Agudos (RESCUE). Resultados: En el contexto extrahospi-talario, más de la mitad de las muertes súbitas cardíacas son secundarias a un infarto agudo de miocardio. En el hospital,

\section{Correspondence:}

*Miguel A. Rodríguez-Ramos

E-mail: mialero@infomed.sld.cu
Available online: 04-12-2020

Arch Cardiol Mex (Eng). 2020;90(3):312-317

www.archivoscardiologia.com 2604-7063 / @ 2020 Instituto Nacional de Cardiología Ignacio Chávez. Published by Permanyer. This is an open access article under the CC BY-NC-ND license (http://creativecommons.org/licenses/by-nc-nd/4.0/). 
la mortalidad en Cuba por IMA es homogénea. Sólo los centros con intervencionismo coronario escapan a este fenómeno. Aunque no del todo letales, las arritmias ventriculares malignas se relacionan con un peor pronóstico y su prevalencia no es homogénea en los registros revisados. Conclusiones: La muerte súbita luego de infarto agudo de miocardio será aún en Cuba una de las principales causas de muerte en los pacientes de fase aguda.

Palabras clave: Muerte súbita cardíaca. Mortalidad hospitalaria. Infarto de miocardio. Infarto de miocardio agudo con eleva-ción del segmento ST.

\section{Introduction}

Heart diseases constitute an important cause of death in developed and developing countries ${ }^{1}$. A large proportion of these occur in patients without a history of pathologies and, although a gradual decline in the prevalence is recorded, the mortality rate for some specific causes remains stable ${ }^{2}$.

Seventy-five percent of out-of-hospital deaths classified as sudden have been reported to be due to coronary artery diseases. These included ventricular tachycardia (VT) as the cause of the final event in $75 \%$ of cases $^{3}$. At present, due to measures for incidence reduction, based on primary and secondary prevention, this figure has decreased, which has contributed to the occurrence of other forms of cardiac arrest, such as asystole and pulseless electrical activity ${ }^{4}$.

In the in-hospital setting, this reduction phenomenon has not been noticeable, and VT and ventricular fibrillation (VF) are still leading causes of cardiac arrest, which is why rescue rates are high in the out-of-hospital setting ${ }^{5}$.

Although there are three cardio-surgical networks in Cuba with the possibility of coronary and surgical interventionism at ruling centers, they are seldom active (24/7) for the reception of patients with acute coronary syndromes (ACS), except perhaps for the Institute of Cardiology and Cardiovascular Surgery. Consequently, secondary care hospitals are the governing entities of the provincial and sectoral networks that provide care to these patients, who are mostly treated with thrombolytic agents rather than with coronary interventionism as suggested by international guidelines.

This work aims to analyze the prevalence of predisposing causes for in-hospital sudden death (SD) after acute myocardial infarction (AMI) in Cuban registries.

\section{Materials and methods}

To identify articles published within the past 3 years in Cuba on AMI hospital records, the Scientific Literature on Line (ScieLO) database and the CorSalud and Revista Cubana de Cardiología y Cirugía Cardiovascular (RCCCCV) files were consulted. All descriptors that in ScieLO appear suggested with the keywords Infarto + Miocardio (Infarction + Myocardium) were reviewed. The same operation was carried out with "Muerte + Súbita" (Death + Sudden) or "Cardiovascular" (Cardiovascular) or "Cardíaca" (Cardiac).

Priority was given to reports with $<3$ years of publication or those that were in editorial process at the time. The CorSalud issue dedicated to SD episodes in 2016 was fully downloaded, as well as the epidemiological records of the Cuban SD Research Group (GIMUS - Grupo de Investigación de Muerte Súbita).

The medline search engine was also used to locate any national report in the main journals. Search engines for the retrieval of information of journals not included in ScieLO, PUBMED and SCOPUS, with the exception of RCCCCV, were not used and, although it is recognized that there might be reports of certain importance therein, they were excluded from the study. The following is the flow chart that was carried out. Search in ScieLO Cuba: "Infarto de miocardio" "Myocardial infarction"): 7 results; "Infarto del miocardio" (Infarction of the myocardium): 51; "Infarto del miocardio agudo" (Acute infarction of the myocardium): 2; "Infarto del miocardio agudo" (AMI): 4; "Infartos del miocardio" (Infarctions of the myocardium): 1; "Muerte cardíaca" (Cardiac death): 1; "Muerte cardíaca súbita" (Sudden cardiac death): 3; "Muerte súbita" (SD): 23; "Muerte súbita cardíaca" (Cardiac SD): 1; "Muerte súbita cardiovascular" (Sudden cardiovascular death): 5; "Infarto agudo de miocardio" (AMI): 5; "Infarto agudo del miocardio" (Acute infarction of the myocardium): 39; "Infarto agudo miocárdico" (Myocardial acute infarction): 1; "Infarto miocárdico" (Myocardial infarction): 1. Search in regional ScieLO: "Muerte súbita en Cuba" (SD in Cuba): 16 overlapping results, 3 new results; and "Infarto miocardio en Cuba" (Myocardial infarction in Cuba): 28 overlapping results, 3 new results. Search in PUBMED for "SCD in Cuba": 19 results.

Definitions. SD was defined as that which is secondary to malignant ventricular arrhythmias (VT and $V F$ ), as well as patients with cardiac rupture and pulseless electrical activity or asystole as form of presentation. In articles that have a focus other than this, 
if it is duly reported, and the results of the analysis are provided based on the above definition, whenever possible.

Data. Since 2014, data of patients admitted for acute coronary syndrome are collected at the Camilo Cienfuegos Hospital cardiology ward. The basic specifications of this registry have been previously published. Each section works with all patients included up to 31 December, 2017: 387 subjects with ST segment elevation AMI (STEAMI) and 323 with non-STEAMI (NSTEA$\mathrm{MI})$. The absence of coronary interventionism practice in most hospitals in Cuba makes it impossible for an anatomical-hemodynamic analysis of the SD after AMI phenomenon to be performed.

Statistics. A database created with SPSS v.17.0 statistical package for Windows was used. Normal and homogeneous sample distribution was verified $(p>$ 0.05), which allowed the performance of parametric tests. Frequency distribution of the numerical variables under study was analyzed, and mean comparisons between related and independent samples were carried out. To verify the strength of the relationship between qualitative variables, Pearson's non-parametric Chi-square test was used and, in situations where more than $20 \%$ of the expected frequencies had values lower than 5, Fisher's exact test was used. To compare quantitative variables means, Student's t-test for independent samples was used. Statistical validation of the research results adopted a significance level of $95 \%(p<0.05)$ for the previously-established degrees of freedom for each one of the presented circumstances. For the relationship between dichotomous variables and the appearance of complications, mortality (SD), or both, as well as isolated mortality, the odds ratio (OR) was calculated, and a 95\% confidence interval $(\mathrm{Cl})$ was established, with statistical difference, if $p<0.05$.

The research was approved by the Ethics Committee and the Scientific Council of the hospital and, although no patient identification data were published, their confidentiality was respected during their handling.

\section{Out-of-hospital SD from AMI}

Up to $15 \%$ of patients with ACS experience SD, and it is the cause of $30 \%$ of ACS deaths ${ }^{6,7}$. Its incidence is the same for patients with STEAMI and NSTEAMI, although it drops to one half in individuals with unstable angina ${ }^{8}$.

In several foreign series, between 6 and $7.5 \%$ of patients had cardiorespiratory arrest (CRA) before the first contact with health services. In the European Society of Cardiology clinical guidelines, the established value is $7 \% 7,8$.

In Cuba, out-of-hospital mortality of patients with AMI not receiving medical care is as high as $30 \%{ }^{9}$. This group includes individuals with complex arrhythmias and also patients with cardiogenic shock, cardiac ruptures, and other causes of sudden and non-SD. However, this figure varies considerably because out-of-hospital records of this phenomenon are infrequent and mostly biased.

In this area, the SD Research Group is leader in research on the subject in Cuba. In a series of 474 subjects who died of $\mathrm{SCD}^{10}$, its prevalence with regard to out-of-hospital total deaths ranged from $8.0 \%$ to $12.1 \%$. In $58.4 \%$ of these subjects, AMI was confirmed as the cause of death. In another of their reports, out of 1000 SDs over 11 years, 247 were classified as $S C D^{11}$, with atherosclerotic lesions of the coronary tree in all cases and coronary thrombus in 134 (63.5\%) being confirmed.

\section{Ventricular arrhythmias in the hospital setting and AMI}

\section{Analysis of records}

As for the presence of CRA in patients who are able to attend a secondary care center, data are more accurate. In a report of the Hermanos Ameijeiras Hospital (HHA - Hospital Hermanos Ameijeiras) ${ }^{12}$, of 465 patients admitted with AMI from January 2007 to January 2016, ventricular-type arrhythmias (VT or VF) were much more common in deceased patients $(58 \%$ vs. $8 \%, p=0.001)$, despite arrhythmias being reported to have occurred in a similar number of patients discharged alive or deceased (63/343 vs. $62 / 79$, respectively). Still, their incidence was actually low (14\%). Patients with NSTEAMI were also observed to have a higher relationship with SD than individuals with STEAMI ( $p=0.001)$, although the data were not recorded in tables to infer this conclusion or to repeat a similar analysis in the Registry of ACS (RESCUE) sample.

In a registry of the Military Central Hospital ${ }^{13}$, no relationship between the occurrence of arrhythmias and death was identified in any of the 273 patients admitted between 2013 and 2016 ( $p=0.2)$. In their data, 258 alive and 14 deceased, the fact that the occurrence of arrhythmias does not really constitute a predisposing factor for a poor prognosis $(5.42 \%$ vs. $14.3 \%)$ is observed, despite the fact that deceased patients with 
arrhythmias almost triple the number of those who did not experience them and were discharged alive. It should be noted that, in this report, the type of arrhythmia the included patients had is not specified, and that this could have modified the obtained results.

However, in a CardioCentro Ernesto Guevara ${ }^{14}$ registry from October 2012 to December 2014, which included 86 patients, a frequency of lethal arrhythmias is described (11 patients, $12.8 \%$ ) that is close to that reported at the international level. Patients who suffered from a previous infarction and VF (5 in total) had a poorer prognosis in comparison with those who experienced an inferior myocardial infarction and VF ( 2 in total), with no differences between the groups of treatment $(5.81 \%$ vs. $2.32 \%, p=0.23)$. Despite the consistency with foreign reports, these patients are reported to have received pharmacological reperfusion treatment, and absence of this procedure constituted an inclusion criterion to participate in the study.

Another report from the same center ${ }^{15}$, with a more inclusive sample of 118 patients, with no date specified, with $6.8 \%$ of malignant arrhythmias, concluded that the leuko-glycemic index (LGI), with a cutoff value at 1235 , showed a sensitivity of $75 \%$ and specificity of $52.6 \%$ for the diagnosis thereof.

Moreover, the polymorph/lymphocyte* glycemia (PLG) index, with a cutoff point of 14.8 , showed sensitivity and specificity of $87.5 \%$ and $61.8 \%$. Despite this relationship, which uses tools that are accessible to centers from underdeveloped countries, very few works with this methodology are reported in Cuba.

In addition, the difference in the frequency of ventricular arrhythmias occurrence in these cohorts from the same center, and with very little time difference in between, stands out.

A similar incidence is referred in the registry of the Intensive Care Unit of the "Dr. Juan Bruno Zayas Alfonso" Hospital from Santiago de Cuba ${ }^{16}$. In 6 years of study, only 135 patients were included in the study (1.8 patient/month of study). Due to the methodology that was followed to present the data, some results of interest were not reported. Ventricular arrhythmias frequency of occurrence was $4.44 \%$ in the studied population. However, differences between ventricular arrhythmias occurrence and status at discharge are obtained: $1.68 \%$ versus $25 \%$ in living and deceased subjects, respectively ( $p=0.001)$; in this study, having ventricular arrhythmias increased the risk of death by at least 3.22 times.
In none of the analyzed reports are more than five patients observed per month of study. If the specific case of RESCUE, STEAMI accounts for almost ten patients/month of study. A possible explanation for this low admission prevalence could be the data collection site. Patients transferred or admitted to intensive care units or tertiary care centers are almost always scarce and complicated. This could suggest patient underreporting, or that those therein admitted have already overcome arrhythmia presentation acute phase, and their prevalence, therefore, decreases at these centers.

Further evidence in favor of the latter comes from the registry of the Institute of Cardiology and Cardiovascular Surgery (ICCCV - Instituto de Cardiología y Cirugía Cardiovascular) ${ }^{17}$, at just $2 \mathrm{~km}$ from the HHA. It is care mean amounts to 7.2 patients/month of study, and its CRA rate was $9 \%$, and was much lower in the subgroup of patients who received primary coronary interventionism in comparison with thrombolyzed subjects $(4.7 \%$ vs. $11.7 \%, p=0.01)$. The report does not include these data for the 68 patients who did not receive reperfusion, and this is, therefore the only conclusion that can be extrapolated to other centers that do not practice interventionism.

\section{Rescue}

At the Camilo Cienfuegos Hospital, data from the RESCUE ${ }^{18}$ showed an incidence of in-hospital SD of $8.8 \%$ for patients with STEAMI. For this analysis, malignant ventricular arrhythmias (VT and VF) were considered, as well as patients with cardiac rupture with pulseless electrical activity as presentation form. If patients with NSTEAMI were included in this analysis, the SD frequency would drop to nearly $6 \%$ since, in this subgroup, the incidence of SD was much lower $(2.8 \%$, $p=0.01$ ).

In this same center, in a previous registry instigated in $2014^{19}$, a mortality due to ventricular arrhythmias of $8.6 \%$ was reported, and nearly $4 \%$ of patients with STEAMI discharged alive experienced them at some point of their hospitalization. Thrombolytic treatment administration, in comparison with not receiving it, behaved as a protective factor by reducing the probability of SD almost to the half, although there was no statistically significant difference $(\mathrm{OR}, 0.52$; $\mathrm{Cl}, 0.247-$ 1.094; $p=0.08$ ). However, thrombolytic agents administration made no difference between patients with SD and those who did not experience it $57.34 \%$ versus $45 \% ; p=0.27$ in the RESCUE sample ${ }^{18}$. The possible difference can be explained because the report by 
Chávez-González et al. included as patients with arrhythmias those who develop them within the $1^{\text {st }} \mathrm{h}$ of evolution.

In the specific case of LGI, although a significant relationship is attained with a cutoff point established at 1303 points, the results differ from those recorded by a group from Cardiocentro de Villa Clara ${ }^{20}$. First, the cutoff point found in the RESCUE sample is too distant (nearly 150 points) from the one described, which entails the existence of heterogeneity between one center and the other in the values when making this prognostic marker extensive, and an area under the curve higher than 0.70 is never achieved, and it only reaches $0.656(\mathrm{Cl}, 0.54-0.77 ; p=0.01)$, which is too far from the value of $0.79(\mathrm{Cl}, 0.77-0.89)$ of the referred group. Much closer to the results of this study is the already-presented report by Castro-Torres ${ }^{15}$, from the same center, who recorded an area of 0.716 $(95 \% \mathrm{Cl}, 0.519-0.913 ; p=0.042)$, with variability between institutions as well; it should be noted that the report by Díaz-Benítez et al. has the purpose to associate LGI with in-hospital complications, without the type being specified.

Regarding the PLG index, RESCUE does not collect data on leukocyte count differential. Nevertheless, based on a possible homogeneity in the polymorph/ lymphocyte ratio, which ranges between 1.7 and 2.2, the final determinant of the PLG index can be inferred to be the value of the latter. However, the obtained result (area, 0.68; $\mathrm{Cl}, 0.56-0.79 ; \mathrm{p}=0.01$ ) is not much higher than that found with this sample for LGI, given that both indices use common parameters.

None of the above articles describes the time of presentation of these arrhythmias, and establishing an irrigation profile based on their time of occurrence is, therefore, impossible. In RESCUE, $50 \%$ of patients died from ventricular arrhythmias occurring on the $1^{\text {st }}$ day and another $30 \%$ on the second.

Finally, the results of the Cuban care networks are not disappointing, although somewhat distant from foreign report indicators, since their results come from records where the treatment of choice is coronary intervention. Perhaps the main bias is in the high rate out-of-hospital mortality of patients with ACS, which favors a decrease in the incidence of patients with ventricular arrhythmias during hospitalization.

\section{Conclusions}

There is large heterogeneity observed in the investigations on in-hospital SD. Apparently, this will not stop being one of the main causes of death of patients in the acute phase of myocardial infarction in Cuba.

\section{Funding}

None.

\section{Conflicts of interest}

The authors declare that they have no conflicts of interest.

\section{Ethical disclosures}

Protection of human and animal subjects. The authors declare that no experiments were performed on humans or animals for this research.

Confidentiality of data. The authors declare that no patient data appear in this article.

Right to privacy and informed consent. The authors declare that no patient data appear in this article.

\section{References}

1. Sanchís-Gomar F, Pérez-Quilis C, Leischik R, Lucía A. Epidemiology of coronary heart disease and acute coronary syndrome. Ann Transl Med. 2016;4(13):256. doi: 10.21037/atm.2016.06.33.

2. Martos-Benítez FD. Mortalidad cardíaca intrahospitalaria: epidemiología y estrategias de prevención. CorSalud 2017;9(2):95-105.

3. Pang BJM, Green MS. Epidemiology of ventricular tachyarrhythmia. Any changes in the past decades? Herzschr Elektrophys. DOI 10.1007/ s00399-017-0503-5.

4. Priori SG, Blomström-Lundqvist C, Mazzanti A. 2015 ESC guidelines for the management of patients with ventricular arrhythmias and the preven-tion of sudden cardiac death. Europace 2015;17(11):euv319.

5. Bière L, Niro M, Pouliquen H, Gourraud JB, Prunier F. Risk of ventricular arrhythmia in patients with myocardial infarction and non-obstructive coronary arteries and normal ejection fraction. World J Cardiol. 2017:9(3):268-276.

6. Yousuf O, Chrispin J, Tomaselli GF, Berger RD. Clinical management and prevention of sudden cardiac death. Circ Res. 2015;116:2020-2040. DOI: $10.1161 / \mathrm{CIRCRESAHA.116.304555.}$

7. Albanese M, Alpaslan K, Ouarrak T, Merguet P, Schneider S, Schöls W. In-hospital major arrhythmias, arrhythmic death and resuscitation after successful primary percutaneous intervention for acute transmural infarc-tion: a retrospective single-centre cohort study. BMC Cardiovascular Disorders (2018) 18:116 https://doi.org/10.1186/s12872-018-0851-z.

8. Ibánez B, James S, Agewall S, Antunes MJ, Bucciarelli-Ducci Ch. 2017 ESC Guidelines for the management of acute myocardial infarction in patients presenting with ST-segment elevation. European Heart Journal 2017;00:1-66. doi:10.1093/eurheartj/ehx393.

9. Armas-Rojas NB, Dueñas-Herrera, de la Noval-García $R$, Ortega-Torres YY, Acosta-González M, Morales-Salinas A. Cardiopatía isquémica en Cuba. Una puesta al día. 2015. RCCCCV 2015;21(3).

10. Ochoa-Montes LA, González-Lugo M, Tamayo-Vicente ND, Gómez de Haz HJ, Correa-Azahares DP. Epidemiología de la muerte súbita cardía-ca. Rev Cubana Hig Epidemiol. [Internet]. 2012 50(1):14-24. Available in: http://scieloprueba.sld.cu/scielo.php?script=sci_arttext\&pi-d=S1561-30032012000100003\&lng=es.

11. Tamayo-Vicente ND, Ochoa-Montes LA, Vilches-Izquierdo E, González-Lu-go M, García-Ones D. Infarto miocárdico crónico como factor de riesgo de muerte súbita cardíaca. Rev Cub Inv Biomed. 2015;34(2):145-156.

12. López-Ramírez $M$, Ramos-Emperador $C$, Gómez-Fernández $M$, Pe-ña-Fernández NE, Fusté-Pedroso W. Factores relacionados con la muer-te súbita en pacientes con infarto agudo de miocardio. CorSalud 2017;9(2):70-79.

13. Martínez-García G, Ravelo-Dopico R. Complicaciones intrahospitalarias del infarto del miocardio con elevación del segmento ST. Revista Cuba-na de Medicina Militar 2016;45(3):332-343. 
14. Castro-Hernández FM, Alonso-Mariño NL, Ramírez-Gómez Jl, Alon-so-Mariño OL. Doble antiagregación plaquetaria en pacientes con infar-to agudo de miocardio con elevación del segmento ST y tratamiento trombolítico. CorSalud 2016;8(4):217-226.

15. Castro-Torres Y, Yar-Khan N, Carmona-Puerta R. Nuevos marcadores de arritmias ventriculares malignas en pacientes con infarto agudo de miocardio con elevación del segmento ST. Resúmenes de trabajos pre-sentados al Concurso Internacional por el Premio «Néstor Acosta Tieles In Memoriam» del II Simposio Nacional de Muerte Súbita Cardiovascular y I Convención Iberoamericana de Muerte Súbita Cardiovascular (6-9 de diciembre de 2016, La Habana, Cuba). CorSalud 2017;9(3): 174-179.

16. Sánchez-Ábalos VM, Bosch-Costrafeda C, Sánchez-Ábalos TM, Gonzá-lez- Blanco JC. Morbilidad y mortalidad por infarto agudo del miocardio. MEDISAN 2014;18(4):516.
17. Martínez-Carrillo A, Sainz González-de la Peña BA, Ramos Gutiérrez B, Pacheco-Álvarez E, Zorio Suárez-BY, Castañeda-Rodríguez G. Infarto agudo con elevación del ST en el servicio de urgencias del Instituto de Cardiología. RCCCCV 2017:23:1.

18. Rodríguez-Ramos MA. Muerte súbita cardiovascular intrahospitralaria e infarto agudo de miocardio con elevación de ST: resultados de RESCUE. CorSalud 2017:9(4):255-262

19. Chávez-González E, Rodríguez-Jiménez AE, Moreno-Martínez FL. Du-ración y dispersión del QRS para predecir arritmias ventriculares en las fases iniciales del infarto agudo de miocardio. Med Intensiva 2017:41(6):347-355. doi: 10.1016/j.medin.2016.09.008

20. Díaz-Benítez RE, Correa-Morales AM, Reyes-Hernández LM, Carva-jal-Sánchez PA, González-Rivera EM, Coronado-Herrera Y. Hemoglobi-na glucosilada e índice leucoglucémico como determinaciones pronósti-cas en el síndrome coronario agudo. CorSalud 2016;8(3):153-163. 